\title{
Evaluation of the Hypothalamic- Pituitary-Adrenal Axis Function in Childhood and Adolescence
}

\author{
George P. Chrousos ${ }^{a}$ b Tomoshige Kino $^{b}$ Evangelia Charmandari ${ }^{a}$ b \\ a Division of Endocrinology and Metabolism, Clinical Research Center, Biomedical Research Foundation of the

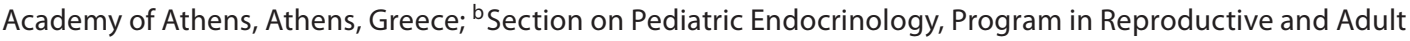 \\ Endocrinology, Eunice Kennedy Shriver National Institute of Child Health and Human Development, \\ National Institutes of Health, Bethesda, Md., USA
}

\section{Key Words}

Hypothalamic-pituitary-adrenal axis · Glucocorticoids · Synacthen test $\cdot$ Dexamethasone suppression test $\cdot$ $\mathrm{CRH}$ test

\begin{abstract}
The hypothalamic-pituitary-adrenal (HPA) axis plays an important role in the maintenance of basal and stress-related homeostasis. The hypothalamus controls the secretion of adrenocorticotropic hormone (ACTH) from the anterior pituitary, which in turn stimulates the secretion of glucocorticoids from the adrenal cortex. Glucocorticoids, the final effectors of the HPA axis, regulate a broad spectrum of physiologic functions essential for life and exert their effects through their ubiquitously distributed intracellular receptors. Alterations in the activity of the HPA axis may present with symptoms and signs of glucocorticoid deficiency or excess. Detailed endocrinologic evaluation is of primary importance in determining the diagnosis and/or etiology of the underlying condition. We review the most common endocrinologic investigations used in the evaluation of the HPA axis integrity and function.
\end{abstract}

Copyright $\odot 2009$ S. Karger AG, Base

\section{Introduction}

The hypothalamic-pituitary-adrenal (HPA) axis plays an important role in the maintenance of basal and stressrelated homeostasis. The stress response is subserved by the stress system, which has both central nervous system (CNS) and peripheral components [1-3]. The central components of the stress system are located in the hypothalamus and the brainstem, and include: (i) the parvocellular neurons of corticotropin-releasing hormone (CRH); (ii) the arginine vasopressin (AVP) neurons of the paraventricular nuclei (PVN) of the hypothalamus; (iii) the $\mathrm{CRH}$ neurons of the paragigantocellular and parabranchial nuclei of the medulla and the locus ceruleus (LC), and (iv) other mostly noradrenergic (NE) cell groups in the medulla and pons (LC/NE system). The peripheral components of the stress system include (i) the peripheral limbs of the HPA axis; (ii) the efferent sympatheticadrenomedullary system, and (iii) components of the parasympathetic system [1-3] (fig. 1a).

$\mathrm{CRH}$, a 41-amino-acid peptide, is the principal hypothalamic regulator of the pituitary-adrenal axis that stimulates the secretion of adrenocorticotropic hormone (ACTH) from the anterior pituitary, which in turn stimulates the secretion of glucocorticoids by the adrenal cortex [4] (fig. 1b). AVP, although a potent synergistic factor

Evangelia Charmandari, MD, Division of Endocrinology and Metabolism

Clinical Research Center, Biomedical Research Foundation of the Academy of Athens

4 Soranou tou Efessiou Street, GR-11527 Athens (Greece)

Tel. +30 2106597546 , Fax +30 2106597545

E-Mail evangelia.charmandari@googlemail.com 
of CRH, has very little ACTH secretagogue activity on its own [5]. A positive reciprocal interaction between CRH and AVP also exists at the level of hypothalamus, with each neuropeptide stimulating the secretion of the other. In non-stressful situations, both CRH and AVP are secreted in the portal system in a circadian, pulsatile and highly concordant fashion [6-9].

The amplitude of the CRH and AVP pulses increases early in the morning, resulting in increases primarily in the amplitude of the pulsatile ACTH and cortisol secretion. Peak ACTH concentrations are usually observed at 04:00-06:00 $\mathrm{h}$ and peak cortisol concentrations follow at 08:00 h. Both ACTH and cortisol are released episodically in pulses every $30-120 \mathrm{~min}$ throughout the day, but the frequency and amplitude are greater in the morning. The hypothalamic content of CRH itself shows a diurnal rhythm, with peak content at about 04:00 h. Diurnal variations in the pulsatile secretion of ACTH and cortisol are often perturbed by changes in lighting, feeding schedules and activity, as well as following stress $[3,10,11]$. During acute stress, there is an increase in the amplitude and synchronization of the PVN CRH and AVP pulsatile release into the hypophyseal portal system. AVP of magnocellular neuron origin is also secreted into the hypophyseal portal system via collateral fibers and the systemic circulation via the posterior pituitary $[9,12]$.

The adrenal cortex is the main target of ACTH, which regulates glucocorticoid and adrenal androgen secretion by the zona fasciculata and reticularis, respectively, and participates in the control of aldosterone secretion by the zona glomerulosa. Pituitary ACTH is a 39 -amino-acid peptide derived from pro-opiomelanocortin (POMC), a 241-amino-acid protein. POMC undergoes a series of proteolytic cleavages, yielding several biologically active peptides [13, 14]. POMC 112-150 is ACTH 1-39, POMC $112-126$ and POMC 191-207 constitute $\alpha$ - and $\beta$-melanocyte-stimulating hormone (MSH), respectively, while POMC 210-241 constitutes $\beta$-endorphin. Only the first 20-24 amino acids of ACTH are needed for its full biological activity, and synthetic ACTH(1-24) is widely used in diagnostic tests of adrenal function. The shorter forms of ACTH have a shorter half-life than native ACTH(1-39) [15]. In addition to ACTH, other hormones, cytokines, and neuronal information from the autonomic nerves of the adrenal cortex may also participate in the regulation of cortisol secretion $[9,16,17]$.

Glucocorticoids are the final effectors of the HPA axis. These hormones are pleiotropic, and exert their effects through their ubiquitously distributed intracellular receptors $[18,19]$. The human glucocorticoid receptor $\alpha$
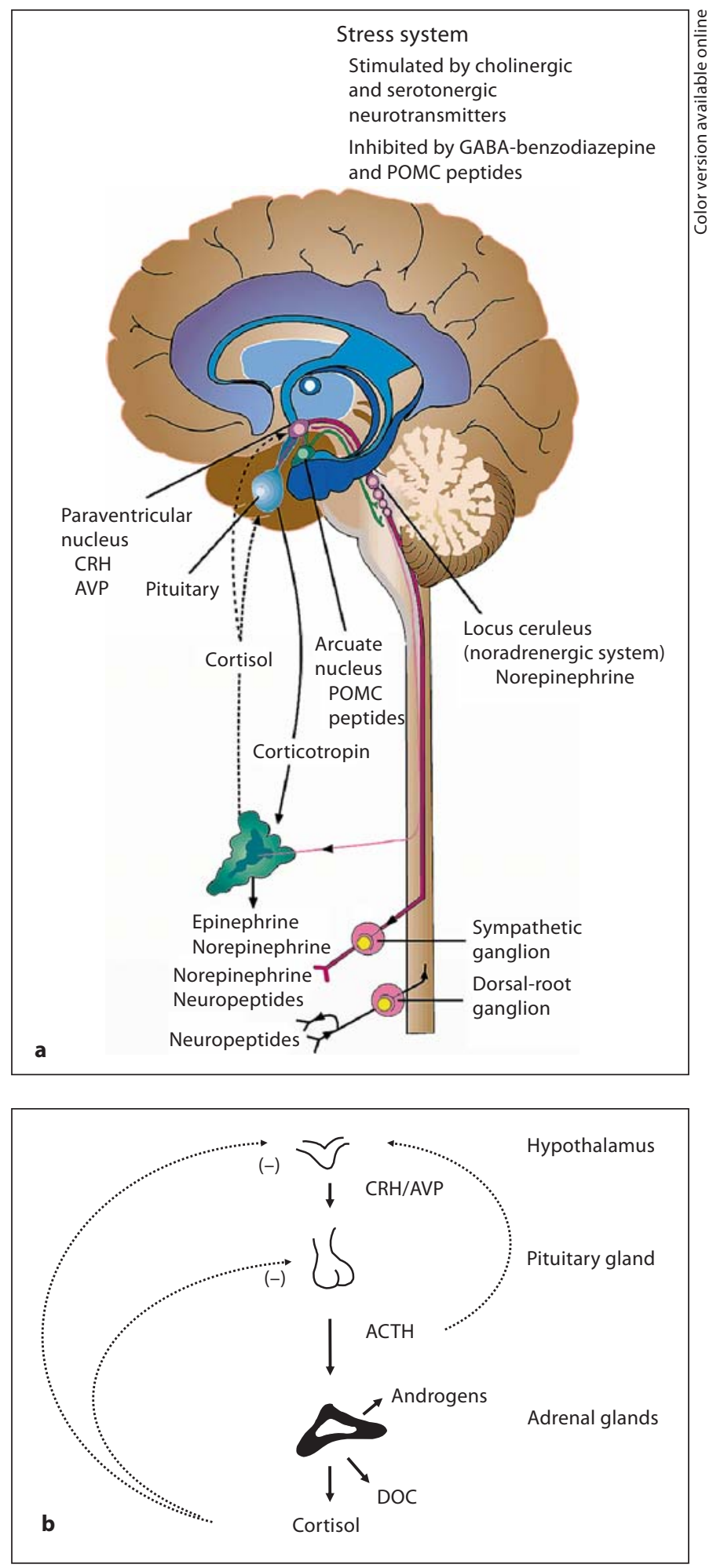

Fig. 1. a Schematic representation of the central and peripheral components of the stress system, their functional interrelations, and their relation to other CNS components involved in the stress response [adapted from 66]. b Schematic representation of the HPA axis. 
(hGR $\alpha$ ) belongs to the steroid/thyroid/retinoic acid nuclear receptor superfamily and functions as a liganddependent transcription factor [20, 21]. In the absence of ligand, hGR $\alpha$ resides mostly in the cytoplasm of cells as part of a hetero-oligomeric complex, which contains chaperon heat-shock proteins (HSPs) 90, 70, 23 and FKBP51, as well as other proteins [22]. Upon ligand-induced activation, the receptor dissociates from this multiprotein complex and translocates into the nucleus, where it binds as a homodimer to glucocorticoid response elements (GREs) in the promoter regions of target genes and regulates their expression positively or negatively, depending on GRE sequence and promoter context [18, 19, 23]. The ligand-activated hGR $\alpha$ can also modulate gene expression independently of DNA binding, by interacting, possibly as a monomer, with other transcription factors, such as nuclear factor $-\kappa \mathrm{B}(\mathrm{NF}-\kappa \mathrm{B})$, activator protein-1 (AP-1), p53 and signal transducers and activators of transcription (STATs) [24-26] (fig. 2).

Glucocorticoids play an important role in the regulation of basal activity of the HPA axis, as well as in the termination of the stress response by acting at extrahypothalamic centers, the hypothalamus and the pituitary gland. The negative feedback of glucocorticoids on the secretion of $\mathrm{CRH}$ and $\mathrm{ACTH}$ serves to limit the duration of the total tissue exposure of the organism to glucocorticoids, thus minimizing the catabolic, lipogenic, antireproductive, and immunosuppressive effects of these hormones (fig. 1b). A dual-receptor system exists for glucocorticoids in the CNS, which includes the glucocorticoid receptor type I or mineralocorticoid receptor that responds to low concentrations of glucocorticoids, and the classic glucocorticoid receptor type II, which corresponds to the classic glucocorticoid receptor and responds to both basal and stress concentrations of glucocorticoids. The negative feedback control of the CRH and ACTH secretion is mediated through type II glucocorticoid receptors [1-3].

\section{Clinical and Laboratory Evaluation of Adrenal Function}

\section{Adrenal Insufficiency}

The most common etiology of primary adrenal insufficiency in the last century was tuberculosis; however, at present autoimmune disease accounts for most cases of primary adrenal insufficiency presenting outside the newborn period. Both these conditions affect the whole of the adrenal cortex, resulting in glucocorticoid, miner- alocorticoid and androgen deficiency. Other conditions that lead to destruction of the adrenal gland include adrenoleukodystrophy, adrenal hemorrhage and adrenal metastases [27]. Adrenal dysgenesis, such as in adrenal hypoplasia congenita (AHC), similarly affects the secretion of all adrenal hormones, while inborn errors of adrenal steroidogenesis, such as in congenital adrenal hyperplasia (CAH) due to 21-hydroxylase deficiency, lead to decreased secretion of glucocorticoids and often mineralocorticoids, and adrenal hyperandrogenism [28, 29].

Secondary adrenal insufficiency is the result of inadequate ACTH secretion from the anterior pituitary, which is most often due to suppression of the HPA axis by longterm glucocorticoid treatment. Other causes of secondary adrenal insufficiency include pituitary or suprasellar tumors, pituitary surgery or pituitary irradiation and congenital anatomical defects, and are often associated with other anterior and/or posterior pituitary hormone deficits [27].

Adrenal insufficiency may be evident prior to performing any investigations. In acute cases, patients present with hypotension, shock, weakness, apathy, confusion, anorexia, nausea, vomiting, dehydration, abdominal or flank pain and hypoglycemia, while in chronic cases patients present with weakness, fatigue, anorexia, weight loss, hypotension and hyperpigmentation [27].

A number of abnormalities on routine laboratory investigations usually indicate the diagnosis of adrenal insufficiency. In primary adrenal insufficiency, hyponatremia, hyperkalemia and metabolic acidosis are common consequences of aldosterone deficiency. Hyponatremia may also be observed in secondary adrenal insufficiency and is due to cortisol deficiency, increased AVP secretion and water retention. Other laboratory abnormalities associated with adrenal insufficiency include hypoglycemia, hypercalcemia (rare), mild normocytic anemia, lymphocytosis and mild eosinophilia. Basal early morning cortisol concentrations (08:00-09:00 h) may be useful in establishing the diagnosis. Morning serum cortisol concentrations of $<150 \mathrm{nmol} / \mathrm{l}$ are highly suggestive of adrenal insufficiency, whereas cortisol concentrations $>525 \mathrm{nmol} / 1 \mathrm{rule}$ out the diagnosis [30, 31]. Random cortisol concentrations are of no value except in patients requiring intensive care treatment, in whom a concentration of $>700 \mathrm{nmol} / \mathrm{l}$ makes the diagnosis of adrenal insufficiency unlikely [32,33]. Simultaneous measurements of cortisol and ACTH concentrations identify most cases of primary adrenal insufficiency. Normal plasma ACTH concentrations may be observed in mild cases of secondary adrenal insufficiency. 
Fig. 2. a General mechanisms of action of glucocorticoids. b Schematic representation of the interaction of activation function (AF)-1 and AF-2 of the glucocorticoid receptor with coactivators. DRIP/TRAP = Vitamin D receptor-interacting protein/ thyroid hormone receptor-associated protein; GR = glucocorticoid receptor; GRE = glucocorticoid response element; HSP = heat-shock protein; $11 \beta$ HSD2 $=11 \beta$-hydroxysteroid dehydrogenase type 2; IL-1 = interleukin-1; LPS = lipopolysaccharide; mRNA $=$ messenger RNA; NF- $\kappa \mathrm{B}=$ nuclear factor $-\kappa \mathrm{B} ; \mathrm{P}=$ phosphate; $\mathrm{SWI} / \mathrm{SNF}=$ switching/sucrose non-fermenting; TNF$\alpha=$ tumor necrosis factor $-\alpha$. Solid arrows denote activation, while dashed arrows denote inhibition and/or repression.
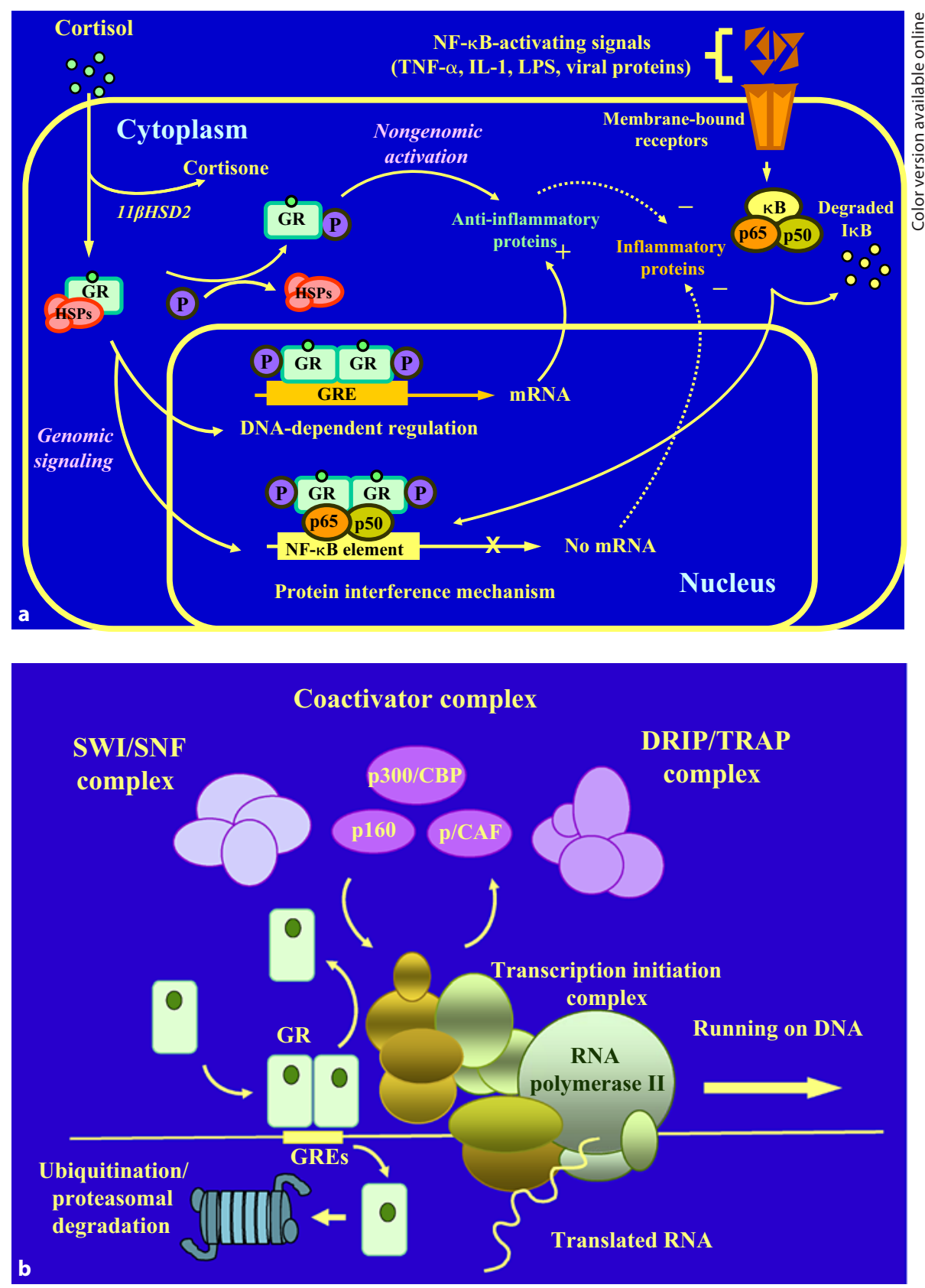

Adrenal cortex antibodies should be measured in all cases of biochemically confirmed primary adrenal insufficiency. In boys who are antibody-negative, serum concentrations of very-long-chain fatty acids should also be measured to exclude adrenoleukodystrophy.

\section{Synacthen Tests}

In the insulin tolerance test (ITT), the cortisol response to hypoglycemia is a reliable test of adrenal func- tion that evaluates the integrity of the entire HPA axis. It represents the only test of adrenal function that has been validated against the response to surgical stress. On the other hand, the synacthen test assesses the response of the adrenal gland to exogenous ACTH administration and evaluates the adrenal rather than the pituitary function. However, given that ACTH plays a critical role in cortisol biosynthesis, it is implicit that a good response to ACTH stimulation indicates an intact axis $[34,35]$. 
Standard Dose or Short Synacthen Test (SDST)

Background/Indications

The test entails stimulation of the adrenal glands by pharmacologic doses of exogenous ACTH(1-24) administered either intravenously (i.v.) or intramuscularly (i.m.). It is indicated for the diagnosis of adrenal insufficiency and $\mathrm{CAH}$, for determination of the heterozygote state in $\mathrm{CAH}$ and for investigation of premature adrenarche [34-36].

\section{Precautions}

The dose of ACTH(1-24) used in the SDST represents an entire day's pituitary output of ACTH. Therefore, it is only of value in assessing severe adrenal insufficiency. The test has proved non-sensitive to mild cases of adrenal insufficiency, such as in patients receiving inhaled steroids [33]. The test is not reliable if it is performed within 4 weeks of pituitary surgery, since ACTH deficiency may not have been sufficiently prolonged to result in adrenal atrophy [36]. The 30-min sample of the SDST has been standardized against the cortisol response to hypoglycemia in the ITT. Severe allergic reactions to synacthen have been described, particularly in children with a history of allergic disorders, but are very rare.

\section{Patient Preparation}

All steroid therapy, other than dexamethasone or betamethasone, interferes with the assay of cortisol. Hydrocortisone therapy should be discontinued for $24 \mathrm{~h}$ (or at least $12 \mathrm{~h}$ ) prior to testing. Prednisone, prednisolone or other interfering therapy should be discontinued for at least 3 days prior to testing. If steroid cover is essential, it can be provided by dexamethasone, since replacement doses of this steroid do not interfere significantly with the adrenal response to ACTH(1-24). Fasting is not required. A reliable cannula should be inserted and the patient should rest for $30 \mathrm{~min}$. It is important that steroid therapy be reinstituted immediately after the completion of the test and while awaiting the results of these investigations.

\section{Protocol}

The test should ideally be performed at 09:00 $\mathrm{h}$. The $\mathrm{ACTH}(1-24)$ dose is administered i.v. (slowly over $2 \mathrm{~min}$ ) or i.m. and is as follows: (i) $36 \mu \mathrm{g} / \mathrm{kg}$ in infants $<6$ months; (ii) $125 \mu \mathrm{g} / \mathrm{kg}$ in children aged 6-24 months, and (iii) 250 $\mu \mathrm{g} / \mathrm{kg}$ in children $>2$ years. Serum cortisol concentrations should be measured at $0,+30$ and +60 min after stimulation. When primary adrenal insufficiency is suspected, ACTH should also be measured at the start of the test. If 21-hydroxylase deficiency is suspected, additional measurements should include: (i) 17-hydroxyprogesterone (17-OHP) at $0,+30$ and $+60 \mathrm{~min}$; (ii) testosterone, androstenedione, DHEA and DHEAS at $0 \mathrm{~min}$, and (iii) urinary steroid analysis. If $11 \beta$-hydroxylase deficiency is suspected, additional measurements should include: (i) 11-deoxycortisol at $0,+30$ and $+60 \mathrm{~min}$; (ii) testosterone, androstenedione, DHEA and DHEAS at $0 \mathrm{~min}$, and (iii) urinary steroid analysis.

\section{Interpretation}

Plasma cortisol concentrations at +30 min should be $>550 \mathrm{nmol} / \mathrm{l}(20 \mu \mathrm{g} / \mathrm{dl})$ or the increment above the basal cortisol concentrations should be $>200 \mathrm{nmol} / \mathrm{l}(7.26 \mu \mathrm{g} /$ $\mathrm{dl})$. It is extremely important that the $30 \mathrm{~min}$ value is used for interpretation because it has been validated against the ITT [37]. It should be noted, however, that the use of a cutoff value of $550 \mathrm{nmol} / \mathrm{l}(20 \mu \mathrm{g} / \mathrm{dl})$ is somewhat arbitrary and has been established using earlier studies in which cortisol was measured by a fluorimetric method. Cortisol values are highly method-dependent and bias differences between methods do not show consistency at different time points $[38,39]$. Due to methodological differences between laboratories, it is advisable that each laboratory establishes its own reference values for cortisol.

An impaired response does not distinguish between adrenal and pituitary insufficiency, since the adrenal glands may be atrophied secondary to ACTH deficiency. Traditionally, the long synacthen test has been used to distinguish between primary and secondary adrenal insufficiency; however, with the improved availability and reliability of ACTH assays, this test has become redundant, since the endogenous ACTH concentrations may be diagnostic of primary adrenal insufficiency (very high). If the basal cortisol concentration is low, then the increment of $>200 \mathrm{nmol} / \mathrm{l}(7.26 \mu \mathrm{g} / \mathrm{dl})$ may suggest the diagnosis of ACTH insufficiency. Patients with secondary adrenal insufficiency may be further evaluated using the CRH test, which may differentiate between hypothalamic and pituitary disease.

In 21-hydroxylase deficiency, the cortisol response may be decreased or normal, but the 17-OHP response is exaggerated with a peak of $>20 \mathrm{nmol} / \mathrm{l}(662 \mathrm{ng} / \mathrm{dl})$. In heterozygotes, the peak 17-OHP concentration is $10-20$ $\mathrm{nmol} / \mathrm{l}(331-662 \mathrm{ng} / \mathrm{dl})$. A peak 17-OHP response of $<10$ $\mathrm{nmol} / \mathrm{l}(331 \mathrm{ng} / \mathrm{dl})$ is normal [40].

\section{Low-Dose Synacthen Test (LDST)}

Background/Indications

The LDST is a modified version of the SDST, which uses a physiologic rather than a pharmacologic dose of 
ACTH(1-24) [34, 35, 41-43]. The SDST does not detect mild degrees of adrenal impairment. Therefore, this modified test has been developed by constructing a doseresponse curve for ACTH(1-24) in terms of the rise in serum cortisol concentrations. An ACTH(1-24) dose of only $500 \mathrm{ng} / 1.73 \mathrm{~m}^{2}$ body surface area results in an identical rise in serum cortisol concentrations over the first 20 min after i.v. injection as compared with the standard dose of $250 \mu \mathrm{g}$. This very low dose of ACTH is now used in an attempt to detect more subtle changes in adrenal function. The LDST is indicated in children who have a normal response to the SDST, but a clinical history or symptomatology suggestive of adrenal insufficiency, such as chronic steroid therapy or hypoglycemia [34, 35].

Patient Preparation

As for the standard dose synacthen test.

Protocol

The LDST should be performed at 14:00 h, when the endogenous secretion of ACTH is at its lowest. The results might not be valid if the LDST is performed at another time. A light lunch should be provided at 12:00 $\mathrm{h}$ and bed rest is recommended from lunch time onwards and until the completion of the test.

At 14:00 $\mathrm{h}$ a blood sample is collected for determination of basal cortisol concentrations. The low dose of $\operatorname{ACTH}(1-24)$ (500 ng $\operatorname{ACTH}(1-24) / 1.73 \mathrm{~m}^{2}$ ) is then administered as an i.v. bolus. Subsequently, blood samples are collected at $+10,+15,+20,+25,+30,+35$ and +40 min after stimulation for determination of serum cortisol concentrations.

\section{Interpretation}

In normal individuals, a peak cortisol concentration of $>550 \mathrm{nmol} / \mathrm{l}(20 \mu \mathrm{g} / \mathrm{dl})$ or an incremental rise of $>200$ $\mathrm{nmol} / \mathrm{l}(7.26 \mu \mathrm{g} / \mathrm{dl})$ above baseline is observed between 15 and $40 \mathrm{~min}$ [42]. In children treated with inhaled or oral steroids, the response may be decreased or blunted. However, if the basal cortisol concentration is low, then the increment of $>200 \mathrm{nmol} / \mathrm{l}(20 \mu \mathrm{g} / \mathrm{dl})$ may still suggest the diagnosis of adrenal insufficiency.

\section{Urine Steroid Profile (USP)}

Background/Indications

A urinary steroid profile examines many steroid metabolites simultaneously and provides specific diagnostic information. Examination of the total 24-hour excretion of steroids is more accurate, given that it eliminates the fluctuations seen in serum samples as a result of time of day, episodic bursts of ACTH and steroid secretion and/ or transient stress. A urinary steroid profile is used predominantly to examine adrenal function. It is also useful for investigating adrenal and gonadal tumors and assists in the diagnosis of disorders of gonadal development, precocious puberty, premature adrenarche and defects in steroidogenesis. It may also assist in the differential diagnosis of Cushing syndrome, hypertension and adrenal suppression. A urinary steroid profile is not indicated in cases of adrenal insufficiency because it cannot reliably differentiate between sufficient and insufficient cortisol production [34].

\section{Patient Preparation}

In neonates, a USP is only useful after day 3 of life because of possible interference by placental steroids. In older children with suspected CAH, a SDST may need to be performed prior to the urine collection for USP in order to stimulate the adrenal glands and amplify any defects in adrenal steroidogenesis. In older children with suspected $5 \alpha$-reductase deficiency, the ratio of $5 \alpha$ - to $5 \beta$ metabolites can be measured in the urine after stimulation of androgen secretion by human chorionic gonadotropin.

\section{Protocol}

A 24-hour collection is required for accurate quantification of urinary steroid excretion rates. Alternatively, a spot or random urine collection may still be helpful in most cases, since quantitative abnormalities of specific metabolites may allow the diagnosis of steroid biosynthetic defects. Hydrocortisone replacement therapy should be discontinued, steroid cover should be provided by equivalent doses of dexamethasone, and a depot preparation of synacthen should be administered before urine collection.

\section{Interpretation}

Congenital adrenal hyperplasia: (i) 21-hydroxylase deficiency is indicated by excess of 17-OHP metabolites; (ii) $11 \beta$-hydroxylase deficiency is indicated by excess of 11 deoxycortisol metabolites; (iii) $3 \beta$-hydroxysteroid dehydrogenase deficiency is suggested by excess of DHEA and pregnenolone; (iv) $17 \alpha$-hydroxylase deficiency is suggested by increased progesterone and corticosterone metabolites (not seen in neonates); (v) in StAR defects, no steroids are identified.

Defects in testosterone biosynthesis or action: (i) $5 \alpha$-reductase deficiency is suggested by elevated $5 \beta$ metabolite: $5 \alpha$-metabolite ratio; (ii) androgen insensitiv- 
ity syndromes are suggested by the elevated androgen metabolites; (iii) 17-hydroxysteroid dehydrogenase deficiency is indicated by the elevated androsterone to etiocholanolone ratio; (iv) adrenarche is suggested by the increased androgen and cortisol output for age and body surface area.

Defects in aldosterone biosynthesis and action: (i) 18hydroxylase deficiency is suggested by the elevated corticosterone concentrations; (ii) 18-oxidation defects are suggested by the increased concentration of 18 -hydroxycorticosterone when concordant plasma aldosterone levels are low; (iii) defects of aldosterone action are suggested by the elevated aldosterone and 18-hydroxycorticosterone levels.

Hypertension: (i) 11 $\beta$-hydroxysteroid dehydrogenase deficiency is suggested by the high ratio of cortisol to cortisone metabolites; (ii) dexamethasone-suppressible hyperaldosteronism is suggested by the increased excretion of 18-hydroxycortisol; generalized glucocorticoid resistance is suggested by the elevated cortisol and androgen metabolites.

Cushing syndrome is suggested by the increased urinary free cortisol excretion. Tumors of the adrenal gland are indicated by an excess of adrenal androgens and/or cortisol excretion. In maternal androgen intake, the child's USP is normal, but there is increased androgen excretion in maternal urine.

\section{Adrenal Hyperfunction/Cushing Syndrome}

The term Cushing syndrome refers to any form of glucocorticoid excess. Cushing disease refers to hypercortisolism due to increased secretion of ACTH by the anterior pituitary, while the related disorder caused by ACTH of non-pituitary origin is termed ectopic ACTH syndrome. Other causes of Cushing syndrome include adrenal adenoma, adrenal carcinoma and multinodular adrenal hyperplasia. Iatrogenic Cushing syndrome refers to hypercortisolism owing to administration of supraphysiologic doses of ACTH or glucocorticoids [44, 45].

Cushing syndrome is rare in childhood and the symptoms may vary; however, the diagnosis should be considered in any child with weight gain and growth failure [4547]. Early signs of glucocorticoid excess include increased appetite, weight gain and growth arrest without a concomitant delay in bone age, while chronic glucocorticoid excess results in typical cushingoid facies, although the buffalo hump and centripetal distribution of body fat may be seen only in long-standing, undiagnosed disease.

The diagnosis and etiology of Cushing syndrome may be difficult to establish. In most cases, the condition is due to a pituitary adenoma, although Cushing syndrome due to an adrenal tumor or adrenal hyperplasia can occur in childhood, especially in children with McCune-Albright syndrome. The ectopic ACTH syndrome is very rare in children [45]. It is essential that the diagnosis of Cushing syndrome is confirmed first before establishing the etiology of the disease.

\section{Initial Investigations Confirming the Diagnosis}

Routine laboratory investigations (full blood count, plasma electrolytes and glucose) may be helpful in the diagnosis and differential diagnosis of Cushing syndrome. Hypokalemia and impaired glucose tolerance are more common in the ectopic ACTH syndrome but do occur in other types of Cushing syndrome. Urinary free cortisol (UFC) measurements provide an integrated measure of cortisol secretion and should be determined on at least three separate 24-hour urine collections [48]. Circadian (08:00 and 24:00 h) serum or salivary cortisol and plasma ACTH measurements should also be determined. One of the earliest biochemical abnormalities in Cushing syndrome independently of etiology is the failure to fully suppress plasma cortisol concentrations at or near its latenight circadian nadir $[44,45]$. Obtaining a stress-free, sleeping midnight blood sample for determination of serum cortisol concentrations is often not possible outside controlled clinical environments. It is now well established that an elevated late-night or bedtime salivary cortisol concentration is an excellent surrogate for increased midnight serum cortisol concentration in the diagnosis of Cushing's syndrome [49-59]. Midnight salivary cortisol measurement is a simple and non-invasive test with sensitivity and specificity $>95 \%$, which has proven extremely useful in the diagnosis of hypercortisolism. As indicated for the collection of serum samples, patients should be requested to abstain from physical activity and food for $3 \mathrm{~h}$ prior to the collection of the saliva sample.

A midnight serum cortisol concentration of $<50$ $\mathrm{nmol} / \mathrm{l}(1.815 \mu \mathrm{g} / \mathrm{dl})$ or a midnight saliva cortisol concentration $<5.52 \mathrm{nmol} / \mathrm{l}(2.0 \mathrm{ng} / \mathrm{ml})$, excludes the diagnosis of Cushing syndrome.

\section{Dexamethasone Suppression Tests}

Dexamethasone is a potent synthetic glucocorticoid that suppresses ACTH secretion by negative feedback inhibition at the hypothalamic and anterior pituitary level, thereby leading to suppression of cortisol secretion. Patients with Cushing syndrome lose the normal negative feedback control and cortisol concentrations fail to suppress. 


\section{Overnight Dexamethasone Suppression Test}

Background/Indications

The test can be performed as an outpatient investigation and is used widely as a screening test. It has good diagnostic sensitivity but poor specificity. Therefore, all patients who fail to suppress will require formal low-dose dexamethasone suppression test (LDDST) [34].

\section{Precautions}

Ensure that the patient is not on any steroid therapy and is not suffering from any major infection or psychological stress. Patients on hepatic enzyme-inducing medication, such as phenytoin, carbamazepine or rifampicin, may rapidly metabolize dexamethasone, leading to falsepositive results, i.e. no suppression. Ideally, these drugs should be discontinued several weeks prior to investigation.

Protocol

Dexamethasone is given orally at a dose of $0.3 \mathrm{mg} / \mathrm{m}^{2}$ at 24:00 h. At 08:00 h the following morning a blood sample is collected for measurement of cortisol and ACTH concentrations (as well as DHEAS, androstenedione and testosterone, if an adrenal androgen-secreting tumor is suspected). Determination of dexamethasone concentrations at 08:00 $\mathrm{h}$ is also suggested to ensure adherence to dexamethasone treatment.

\section{Interpretation}

In normal individuals, the cortisol concentration at 08:00 $\mathrm{h}$ following administration of dexamethasone should be suppressed ( $<50 \mathrm{nmol} / \mathrm{l}$ or $1.815 \mu \mathrm{g} / \mathrm{dl}$ ). Patients with Cushing syndrome fail to suppress adequately. If the cortisol concentration is not suppressed, a 48 hour LDDST test should be performed. In adrenal androgen-secreting tumors, failure of suppression of adrenal androgens is observed.

Low-Dose Dexamethasone Suppression Test (LDDST) Background/Indications

The LDDST assists further in the differentiation of Cushing syndrome from simple obesity $[34,44-46]$.

\section{Precautions/Patient Preparation}

These are as for the overnight dexamethasone suppression test. Care should be taken in patients with diabetes mellitus.

\section{Protocol}

Day 1: Blood samples for cortisol and ACTH concentrations should be taken at 08:00 h (LDDST 0) and dexamethasone be given at a dose of $7.5 \mu \mathrm{g} / \mathrm{kg} / \mathrm{dose}$ (if body weight $<40 \mathrm{~kg}$ ) or $10 \mu \mathrm{g} / \mathrm{kg} /$ dose (if body weight $>40 \mathrm{~kg}$ ) to maximum of $0.5 \mathrm{mg}$ orally 6-hourly at 09:00, 15:00 and 21:00 h.

Day 2: Dexamethasone is given at 03:00, 09:00, 15:00 and 21:00 h. At 09:00 h (LDDST +24) a 24-hour urine collection for measurement of UFC (and/or other steroids if an adrenal tumor is suspected) is started.

Day 3: The last dose of dexamethasone is given at 03:00 $\mathrm{h}$ and a blood sample for cortisol, ACTH and dexamethasone is collected at 08:00 $\mathrm{h}$ (LDDST +48$)$. The 24-hour urine collection is completed at 09:00 h.

If an androgen-secreting tumor is suspected, DHEAS, androstenedione and testosterone should also be measured.

\section{Interpretation}

In normal individuals and patients with obesity or other non-Cushing disorders, 08:00 h plasma cortisol concentration is in the normal resting range at LDDST 0 and suppresses to $<50 \mathrm{nmol} / \mathrm{l}(1.815 \mu \mathrm{g} / \mathrm{dl})$ at LDDST +48 . Serum testosterone and other adrenal androgens are also decreased at LDDST +48 . UFC concentrations are undetectable. Patients with Cushing syndrome fail to suppress to low-dose dexamethasone. In the latter group, a pretest 08:00 h ACTH concentration of $<5 \mathrm{pg} / \mathrm{ml}$ is highly suggestive of an adrenal cause of Cushing syndrome.

\section{Differential Diagnosis of Cushing Syndrome}

Plasma ACTH Concentrations

ACTH measurement is the first step in the differential diagnosis of Cushing syndrome. Patients with adrenal tumors or non-ACTH bilateral adrenal hyperplasia (very rare) will have undetectable plasma ACTH concentrations. In these patients, CT or MRI scanning of the abdomen will localize the lesion.

High-Dose Dexamethasone Suppression Test

(HDDST)

Background/Indications

This test is indicated in order to establish the etiology of Cushing syndrome [34, 44-46].

Precautions/Patient Preparation

These are as for the overnight and LDDSTs. Care should be taken in patients with diabetes mellitus. 
Protocol

This test may conveniently follow the LDDST (LDDST $+48=$ HDDST 0 ). In this case, the basal value used for the interpretation of the test is the LDDST 0 cortisol level.

Day 0: At 09:00 h (HDDST 0) a 24-hour urine collection for measurement of UFC (and/or other steroids if an adrenal tumor is suspected) is started.

Day 1: Blood samples for cortisol and ACTH concentrations are taken at 08:00 $\mathrm{h}$ (LDDST +48; HDDST 0). Dexamethasone is given at a dose of $40 \mu \mathrm{g} / \mathrm{kg} /$ dose (to maximum of $2 \mathrm{mg}$ ) orally 6-hourly at 09:00, 15:00 and 21:00 h.

Day 2: Dexamethasone is given at 03:00, 09:00, 15:00 and 21:00 h. At 09:00 h (HDDST +24) a 24-hour urine collection for measurement of UFC (and/or other steroids if an adrenal tumor is suspected) is started.

Day 3: A last dose of dexamethasone is given at 03:00 $\mathrm{h}$ and a blood sample for cortisol, ACTH and dexamethasone is taken at 08:00 h (HDDST +48). The 24-hour urine collection is completed at 09:00 h.

If an androgen-secreting tumor is suspected, DHEAS, androstenedione and testosterone should also be measured.

\section{Interpretation}

Patients with Cushing disease classically respond with suppression of ACTH, cortisol (50\% or less of the basal value) and urinary steroids during the high-dose dexamethasone but not during the LDDST. However, some children, especially those early in the course of their illness, may exhibit partial suppression in response to lowdose dexamethasone. Therefore, if the low dose given exceeds $20 \mu \mathrm{g} / \mathrm{kg} /$ day or if the assays used are insufficiently sensitive to distinguish partial from complete suppression, false-negative tests may result in a diagnosis of pituitary-dependent Cushing disease. Patients with adrenal adenoma, adrenal carcinoma or the ectopic ACTH syndrome have values relatively insensitive to both low- and high-dose dexamethasone, although some patients with multinodular adrenal hyperplasia may respond to high-dose dexamethasone.

\section{CRH Stimulation Test}

Background/Indications

$\mathrm{CRH}$ is a test of pituitary ACTH reserve. The $\mathrm{CRH}$ test may be useful in distinguishing hypothalamic from pituitary causes of ACTH deficiency. In conjunction with petrosal sinus sampling, this test may also be useful in establishing the diagnosis of pituitary, ACTH-dependent Cushing disease $[34,45,46,48,60]$.
Precautions/Patient Preparation

The patient should not be on steroid therapy. Patient preparation regarding discontinuation of steroid therapy is as for the standard-dose synacthen test.

The patient should be fasted from midnight $(6 \mathrm{~h}$ in children aged $<2$ years). If both CRH and HDDST are to be performed, the $\mathrm{CRH}$ test must be completed first. An indwelling cannula should be inserted at least $3 \mathrm{~h}$ prior to testing. CRH may cause mild facial flushing.

\section{Protocol}

Blood samples for cortisol and ACTH are taken at -15 and $0 \mathrm{~min}$, and $\mathrm{CRH}_{41}$ is given at a dose of $1 \mu \mathrm{g} / \mathrm{kg}$ (up to a maximum of $100 \mu \mathrm{g}$ ) i.v. over $30 \mathrm{~s}$ at 09:00 h. Further blood samples for cortisol and ACTH concentrations are taken at $+15,+30,+45,+60,+90$ and +120 min after CRH administration.

\section{Interpretation}

In normal subjects, ACTH peaks at approximately 30 min and cortisol at 45-60 min after CRH stimulation. Plasma ACTH rises to $28-231 \mathrm{pg} / \mathrm{ml}$ (usually $<100$ ), while serum cortisol rises to $430-820 \mathrm{nmol} / \mathrm{l}(15.6-30 \mu \mathrm{g} / \mathrm{dl})$.

Secondary Adrenal Insufficiency

A flat ACTH and cortisol response suggests pituitary disease, whereas a delayed and exaggerated ACTH response suggests hypothalamic disease.

\section{Cushing Syndrome}

Patients with pituitary Cushing disease typically show an exaggerated response with an increase in $\mathrm{ACTH}>50 \%$ above the basal concentration and an increase in cortisol concentration $>20 \%$ above the basal concentration $[45$, $46,48]$. In ectopic ACTH secretion, basal ACTH concentrations are high and there is no further response to $\mathrm{CRH}$ stimulation. The false-negative rate of the test is $10-$ $15 \%$.

Petrosal Sinus Sampling Combined with CRH

A central to peripheral ACTH ratio of $>2$ basally and $>3$ after CRH stimulation is necessary to diagnose Cushing disease with confidence [61].

\section{Dexamethasone-Suppressed CRH Stimulation Test}

Background/Indications

The dexamethasone-suppressed CRH stimulation test is a useful test that differentiates mild Cushing's disease from normal physiology, as well as pseudo-Cushing states, such as depression, stress, renal failure, alcoholism 
or obesity. The test is performed immediately after completion of the LDDST $[62,63]$.

\section{Precautions/Patient Preparation}

The patient should not be on any other steroid therapy. Patient preparation regarding discontinuation of steroid therapy is as for the standard-dose synacthen test.

The patient should be fasted from midnight $(6 \mathrm{~h}$ in children aged $<2$ years). An indwelling cannula should be inserted at least $3 \mathrm{~h}$ prior to testing. $\mathrm{CRH}$ may cause mild facial flushing.

\section{Protocol}

The LDDST is performed as described above. Two hours after completion of the LDDST, blood samples for cortisol and ACTH are taken at -15 and $0 \mathrm{~min}$, and $\mathrm{CRH}_{41}$ is given at a dose of $1 \mu \mathrm{g} / \mathrm{kg}$ (up to a maximum of $100 \mu \mathrm{g}$ ) i.v. over $30 \mathrm{~s}$ at 09:00 h. Further blood samples for cortisol and ACTH concentrations are taken at $+15,+30,+45$, $+60,+90$ and +120 min after CRH administration. A blood sample for determination of dexamethasone concentrations is also taken at $0 \mathrm{~min}$, immediately prior to $\mathrm{CRH}$ stimulation.

\section{Interpretation}

In all subjects, ACTH peaks at approximately $30 \mathrm{~min}$ and cortisol at 45-60 min after dexamethasone-suppressed CRH stimulation. Serum cortisol concentrations obtained $15 \mathrm{~min}$ after $\mathrm{CRH}$ stimulation are suppressed $(<38 \mathrm{nmol} / \mathrm{l}, 1.38 \mu \mathrm{g} / \mathrm{dl})$ in normal subjects and patients with pseudo-Cushing states, but $>38 \mathrm{nmol} / \mathrm{l}(1.38 \mu \mathrm{g} / \mathrm{dl})$ in patients with mild Cushing disease.

\section{CRH Stimulation Test following an Overnight}

Dexamethasone Suppression Test

Background/Indications

Exaggerated ACTH and cortisol response to the dexamethasone-suppressed $\mathrm{CRH}$ test, indicating impaired regulation of the HPA axis, is frequently observed in depression. An alternative protocol of the dexamethasonesuppressed $\mathrm{CRH}$ test (following an overnight, singledose, dexamethasone suppression) has been used successfully in differentiating depression from normal physiology, as well as in serving as a biomarker for response to antidepressant therapy $[64,65]$.

\section{Precautions/Patient Preparation}

The patient should not be on any other steroid therapy. Patient preparation regarding discontinuation of steroid therapy is as for the standard-dose synacthen test.
The patient should be fasted from midnight $(6 \mathrm{~h}$ in children aged $<2$ years). An indwelling cannula should be inserted at least $3 \mathrm{~h}$ prior to testing. CRH may cause mild facial flushing.

\section{Protocol}

The overnight single-dose dexamethasone suppression test is performed as indicated above. Accordingly, $1.5 \mathrm{mg}$ of dexamethasone is given orally at 23:00 $\mathrm{h}$ the day before CRH stimulation. On the day of the testing, blood samples for cortisol and ACTH are taken at -15 and 0 min, and $\mathrm{CRH}_{41}$ is given at a dose of $1 \mu \mathrm{g} / \mathrm{kg}$ (up to a maximum of $100 \mu \mathrm{g})$ i.v. over $30 \mathrm{~s}$ at 15:00 h. Further blood samples for cortisol and ACTH concentrations are taken at $+15,+30$, $+45,+60,+90$ and +120 min after CRH stimulation.

\section{Interpretation}

Increased ACTH and cortisol responses to the dexamethasone-suppressed CRH test are observed in patients with depression compared with normal subjects. Patients with depression who respond to antidepressant therapy display an attenuated cortisol and ACTH response to $\mathrm{CRH}$ stimulation compared to the non-responders. These alterations in HPA axis activity may serve as a potential biomarker that may predict clinical outcome [65].

\section{Imaging Studies}

Very small tumors can be visualized using CT scanning and indium-labeled octreotide for bronchial tumors and MRI scanning for pituitary tumors. However, falsepositive results may often occur. Therefore, imaging studies should be interpreted in the context of clinical manifestations and endocrinologic evaluation [34].

\section{Conclusions}

The integrity of the HPA axis is assessed by a number of endocrinologic investigations, including both basal and dynamic testing, which alone or in combination provide invaluable information on the hypothalamic, pituitary and adrenal function. It is particularly important that these investigations are performed according to standardized, validated protocols to ensure accurate results that will allow the correct diagnosis to be established. Particular attention should be given to special precautions, patient preparation, timing of the test, dose of medication and timing of sampling. Interpretation of the results should take into consideration both clinical presentation and assay methodology. 


\section{References}

1 Habib KE, Gold PW, Chrousos GP: Neuroendocrinology of stress. Endocrinol Metab Clin North Am 2001;30:695-728.

2 Chrousos GP: Organization and integration of the endocrine system; in Sperling M (ed): Pediatric Endocrinology. Philadelphia, Saunders, 2002, pp 1-14.

3 Charmandari E, Tsigos C, Chrousos G: Endocrinology of the stress response. Annu Rev Physiol 2005;67:259-284.

4 Vale WW, Spiess S, Rivier C, Rivier J: Characterization of a 41-residue ovine hypothalamic peptide that stimulates secretion of corticotrophin and $\beta$-endorphin. Science 1981;213:1394-1397.

5 Gillies GE, Linton EA, Lowry PJ: Corticotropin-releasing activity of the new CRF is potentiated several times by vasopressin. $\mathrm{Na}$ ture 1982;299:355-357.

6 Horrocks PM, Jones AF, Ratcliffe WA, Holder G, White A, Holder R, Ratcliffe JG, London DR: Patterns of ACTH and cortisol pulsatility over twenty-four hours in normal males and females. Clin Endocrinol (Oxf) 1990;32:127-134.

7 Iranmanesh A, Lizarralde G, Short D, Veldhuis JD: Intensive venous sampling paradigms disclose high frequency adrenocorticotropin release episodes in normal men. J Clin Endocrinol Metab 1990;71:1276-1283.

8 Veldhuis JD, Iranmanesh A, Johnson ML, Lizarralde G: Amplitude, but not frequency, modulation of adrenocorticotropin secretory bursts gives rise to the nyctohemeral rhythm of the corticotropic axis in man. J Clin Endocrinol Metab 1990;71:452-463.

9 Calogero AE, Norton JA, Sheppard BC, Listwak SJ, Cromack DT, Wall R, Jensen RT, Chrousos GP: Pulsatile activation of the hypothalamic-pituitary-adrenal axis during major surgery. Metabolism 1992;41:839-845.

10 Wallace WH, Crowne EC, Shalet SM, Moore C, Gibson S, Littley MD, White A: Episodic ACTH and cortisol secretion in normal children. Clin Endocrinol (Oxf) 1991;34:215221.

11 Tannenbaum BM, Brindley DN, Tannenbaum GS, Dallman MF, McArthur MD, Meaney MJ: High-fat feeding alters both basal and stress-induced hypothalamic-pituitary-adrenal activity in the rat. Am J Physiol 1997;273:E1168-E1177.

12 Holmes MC, Antoni FA, Aguilera G, Catt KJ: Magnocellular axons in passage through the median eminence release vasopressin. Nature 1986;319:326-329.

13 Miller WL, Johnson LK, Baxter JD, Roberts JL: Processing of the precursor to corticotropin and $\beta$-lipotropin in humans. Proc Natl Acad Sci USA 1980;77:5211-5215.

14 Whitfeld PL, Seeburg PH, Shine J: The human pro-opiomelanocortin gene: organization, sequence, and interspersion with repetitive DNA. DNA 1982;1:133-143.
15 Lundblad JR, Roberts JL: Regulation of proopiomelanocortin gene expression in pituitary. Endocr Rev 1988;9:135-158.

16 Andreis PG, Neri G, Mazzocchi G, Musajo F, Nussdorfer GG: Direct secretagogue effect of corticotropin-releasing factor on the rat adrenal cortex: the involvement of the zona medullaris. Endocrinology 1992;131:69-72.

17 Bornstein SR, Chrousos GP: Clinical review 104: Adrenocorticotropin (ACTH)- and non-ACTH-mediated regulation of the adrenal cortex: neural and immune inputs. J Clin Endocrinol Metab 1999;84:1729-1736.

18 Bamberger CM, Schulte HM, Chrousos GP: Molecular determinants of glucocorticoid receptor function and tissue sensitivity to glucocorticoids. Endocr Rev 1996;17:245261.

19 Schaaf MJ, Cidlowski JA: Molecular mechanisms of glucocorticoid action and resistance. J Steroid Biochem Mol Biol 2002;83: 37-48.

20 Zhou J, Cidlowski JA: The human glucocorticoid receptor: one gene, multiple proteins and diverse responses. Steroids 2005;70: 407-417.

21 Duma D, Jewell CM, Cidlowski JA: Multiple glucocorticoid receptor isoforms and mechanisms of post-translational modification. Steroid Biochem Mol Biol 2006;102:11-21.

22 Pratt WB: The role of heat-shock proteins in regulating the function, folding, and trafficking of the glucocorticoid receptor. J Biol Chem 1993;268:21455-21458.

23 Terry LJ, Shows EB, Wente SR: Crossing the nuclear envelope: hierarchical regulation of nucleocytoplasmic transport. Science 2007; 318:1412-1416.

24 Jonat C, Rahmsdorf HJ, Park KK, Cato AC, Gebel S, Ponta H, Herrlich P: Antitumor promotion and anti-inflammation: down-modulation of AP-1 (Fos/Jun) activity by glucocorticoid hormone. Cell 1990;62:1189-1204.

25 Scheinman RI, Gualberto A, Jewell CM, Cidlowski JA, Baldwin AS Jr: Characterization of mechanisms involved in transrepression of NF- $\kappa \mathrm{B}$ by activated glucocorticoid receptors. Mol Cell Biol 1995;15:943-953.

26 Chrousos GP, Kino T: Intracellular glucocorticoid signaling: a formerly simple system turns stochastic. Sci STKE 2005;2005:pe48.

27 Charmandari E, Chrousos GP: Adrenal Insufficiency; in Martini L (ed): Encyclopedia of Endocrine Diseases. San Diego, Elsevier, 2004, pp 75-80.

28 Ferraz-de-Souza B, Achermann JC: Disorders of adrenal development. Endocr Dev 2008;13:19-32.

29 Speiser PW, White PC: Congenital adrenal hyperplasia. N Engl J Med 2003;349:776788.

30 Oelkers W: Adrenal insufficiency. N Engl J Med 1996;335:1206-12.
31 Pizarro CF, Troster EJ, Damiani D, Carcillo JA: Absolute and relative adrenal insufficiency in children with septic shock. Crit Care Med 2005;33:855-859.

32 Vermes I, Beishuizen A, Hampsink RM, Haanen C: Dissociation of plasma adrenocorticotropin and cortisol levels in critically ill patients: possible role of endothelin and atrial natriuretic hormone. J Clin Endocrinol Metab 1995;80:1238-1242.

33 Charmandari E, Lichtarowicz-Krynska EJ, Hindmarsh PC, Johnston A, Aynsley-Green A, Brook CG: Congenital adrenal hyperplasia: management during critical illness. Arch Dis Child 2001;85:26-28.

34 Walker JM, Hughes IA: Tests and normal values in pediatric endocrinology; in Brook CGD (ed): Clinical Pediatric Endocrinology. Oxford, Blackwell, 1996, pp 782-798.

35 Agwu JC, Spoudeas H, Hindmarsh PC, Pringle PJ, Brook CG: Tests of adrenal insufficiency. Arch Dis Child 1999;80:330-333.

36 Gleeson HK, Walker BR, Seckl JR, Padfield PL: Ten years on: safety of short synacthen tests in assessing adrenocorticotropin deficiency in clinical practice. J Clin Endocrinol Metab 2003;88:2106-2111.

37 Lashansky G, Saenger P, Fishman K, Gautier T, Mayes D, Berg G, Di Martino-Nardi J, Reiter E: Normative data for adrenal steroidogenesis in a healthy pediatric population: age- and sex-related changes after adrenocorticotropin stimulation. J Clin Endocrinol Metab 1991;73:674-686.

38 Barth JH, Seth J, Howlett TA, Freedman DB: A survey of endocrine function testing by clinical biochemistry laboratories in the UK. Ann Clin Biochem 1995;32:442-449.

39 Clark PM, Neylon I, Raggatt PR, Sheppard MC, Stewart PM: Defining the normal cortisol response to the short synacthen test: implications for the investigation of hypothalamic-pituitary disorders. Clin Endocrinol (Oxf) 1998;49:287-292.

40 Wallace AM: Analytical support for the detection and treatment of congenital adrenal hyperplasia. Ann Clin Biochem 1995;32:927.

41 Rasmuson S, Olsson T, Hagg E: A low-dose ACTH test to assess the function of the hypothalamic-pituitary-adrenal axis. Clin Endocrinol (Oxf) 1996;44:151-156.

42 Crowley S, Hindmarsh PC, Holownia P, Honour JW, Brook CGD: The use of low doses of ACTH in the investigation of adrenal function in man. J Endocrinol 1991;130: 475-479.

43 Bridges NA, Hindmarsh PC, Pringle PJ, Honour JW, Brook CGD: Cortisol, androstenedione, dehydroepiandrosterone sulphate and 17-hydroxyprogesterone responses to low doses of ACTH(1-24). J Clin Endocrinol Metab 1998;83:3750-3753. 
44 Newell-Price J, Bertagna X, Grossman AB, Nieman LK: Cushing's syndrome. Lancet 2006;367:1605-1617.

45 Storr HL, Chan LF, Grossman AB, Savage MO: Paediatric Cushing's syndrome: epidemiology, investigation and therapeutic advances. Trends Endocrinol Metab 2007; 18: 167-174.

46 Batista DL, Riar J, Keil M, Stratakis CA: Diagnostic tests for children who are referred for the investigation of Cushing syndrome. Pediatrics 2007;120:e575-e586.

47 Savage MO, Chan LF, Afshar F, Plowman PN, Grossman AB, Storr HL: Advances in the management of paediatric Cushing's disease. Horm Res 2008;69:327-333.

48 Perry LA, Grossman AB: The role of the laboratory in the diagnosis of Cushing's syndrome. Ann Clin Biochem 1997;34:345359.

49 Newell-Price J, Trainer P, Perry L, Wass J, Grossman A, Besser M: A single sleeping midnight cortisol has $100 \%$ sensitivity for the diagnosis of Cushing's syndrome. Clin Endocrinol (Oxf) 1995;43:545-550.

50 Papanicolaou DA, Yanovski JA, Cutler GB, Chrousos GP, Nieman LK: A single midnight cortisol measurement distinguishes Cushing's syndrome from pseudo-Cushing's states. J Clin Endocrinol Metab 1998;83: 1163-1167.

51 Gorges R, Knappe G, Gerl H, Ventz M, Stahl F: Diagnosis of Cushing's syndrome: re-evaluation of midnight plasma cortisol vs. urinary free cortisol and low-dose dexamethasone suppression test in a large patient group J Endocrinol Invest 1999;22:241-249.

52 Reimondo G, Allasino B, Bovio S, Paccotti P, Angeli A, Terzolo M: Evaluation of the effectiveness of midnight serum cortisol in the diagnostic procedures for Cushing's syndrome. Eur J Endocrinol 2005;153:803-809.
53 Martinelli CE, Sader SL, Oliveira EB, Daneluzzi JC, Moreira AC: Salivary cortisol for screening of Cushing's syndrome in children. Clin Endocrinol (Oxf) 1999;51:67-71.

54 Raff H, Raff JL, Findling JW: Late-night salivary cortisol as a screening test for Cushing's syndrome. J Clin Endocrinol Metab 1998:83:2681-2686.

55 Gafni RI, Papanicolaou DA, Nieman LK: Nighttime salivary cortisol measurement as a simple, noninvasive, outpatient screening test for Cushing's syndrome in children and adolescents. J Pediatr 2000;137:30-35.

56 Papanicolaou DA, Mullen N, Kyrou I, Nieman LK: Nighttime salivary cortisol: a useful test for the diagnosis of Cushing's syndrome. J Clin Endocrinol Metab 2002;87: 455-4521.

57 Viardot A, Huber P, Puder JJ, Zulewski H, Keller U, Muller B: Reproducibility of nighttime salivary cortisol and its use in the diagnosis of hypercortisolism compared with urinary free cortisol and overnight dexamethasone suppression test. J Clin Endocrinol Metab 2005;90:5730-5736.

58 Yaneva M, Mosnier-Pudar H, Dugue MA Grabar S, Fulla Y, Bertagna X: Midnight salivary cortisol for the initial diagnosis of Cushing's syndrome of various causes. J Clin Endocrinol Metab 2004;89:3345-3351.

59 Putignano P, Toja P, Dubini A, Giraldi FP, Corsella SM, Cavagnini F: Midnight salivary cortisol versus urinary free and midnight serum cortisol as screening tests for Cushing's syndrome. J Clin Endocrinol Metab 2003;88: 4153-4157.
60 Nieman LK, Oldfield EH, Wesley R, Chrousos GP, Loriaux DL, Cutler GB Jr: A simplified morning ovine corticotropin-releasing hormone stimulation test for the differential diagnosis of adrenocorticotropin-dependent Cushing's syndrome. J Clin Endocrinol Metab 1993;77:1308-1312.

61 Oldfield EH, Doppman JL, Nieman LK, Chrousos GP, Miller DL, Katz DA, Cutler GB Jr, Loriaux DL: Petrosal sinus sampling with and without corticotropin-releasing hormone for the differential diagnosis of Cushing's syndrome. N Engl J Med 1991;325:897905.

62 Yanovski JA, Cutler GB Jr, Chrousos GP, Nieman LK:The dexamethasone-suppressed corticotropin-releasing hormone stimulation test differentiates mild Cushing's disease from normal physiology. J Clin Endocrinol Metab 1998;83:348-352.

63 Nieman LK, Biller BM, Findling JW, NewellPrice J, Savage MO, Stewart PM, Montori VM: The diagnosis of Cushing's syndrome: an Endocrine Society Clinical Practice Guideline. J Clin Endocrinol Metab 2008;93: 1526-1540.

64 Heuser I, Yassouridis A, Holsboer F: The combined dexamethasone/CRH test: a refined laboratory test for psychiatric disorders. J Psychiatr Res 1994;28:341-356.

65 Ising M, Horstmann S, Kloiber S, Lucae S, Binder EB, Kern N, Künzel HE, Pfennig A, Uhr M, Holsboer F: Combined dexamethasone/corticotropin-releasing hormone test predicts treatment response in major depression - a potential biomarker? Biol Psychiatry 2007;62:47-54.

66 Chrousos GP: The hypothalamic-pituitaryadrenal axis and immune-mediated inflammation. N Engl J Med 1995;332:1351-1362. 